\title{
Performance Analysis of Composite Magnetic Circuit Permanent Magnet Wind Generator
}

\author{
Gensheng Li, Zongxiao Yang, Ximei Li \\ Institute of Systems Science and Engineering, Henan Engineering Laboratory of Wind Power Systems, Henan University of \\ Science and Technology, Luoyang, China \\ Email:1gs911@126.com
}

How to cite this paper: Li, G.S., Yang, Z.X. and Li, X.M. (2019) Performance Analysis of Composite Magnetic Circuit Permanent Magnet Wind Generator. World Journal of Engineering and Technology, 7, 18-25. https://doi.org/10.4236/wjet.2019.74B003

Received: October 16, 2019

Accepted: November 10, 2019

Published: November 13, 2019

\begin{abstract}
In order to reduce the starting wind speed of the wind wheel and improve the efficiency of the wind wheel, this paper proposes a new type of composite magnetic circuit permanent magnet generator, which changes the relationship between the magnetic induction intensity and the air gap by changing the structure of the main magnetic circuit. The structure greatly improves the air gap sensitivity of the generator, which makes the structural design of the permanent magnet generator easier to implement. Finally, the effectiveness and feasibility of the method are verified by simulation.
\end{abstract}

\section{Keywords}

Composite Magnetic Circuit, Generator, Starting Wind Speed, Main Magnetic Circuit

\section{Introduction}

As the clean energy with the most industrial development potential, wind power has become an important part of the energy structure and is closely related to economic development [1] [2] [3] [4]. China's National Energy Administration's "Twelfth Five-Year Plan for Wind Power Development" predicts that by 2020, the total installed capacity of wind power in China will exceed 200 million kilowatts, and the annual power generation of wind power industry will reach 390 billion kilowatt-hours, which will exceed the $5 \%$ of power generation in China. The actual exploitable wind energy resource reserves of China's $10 \mathrm{~m}$ level are 253 million KW, and the matching low wind speed wind power technology has become one of the most promising research fields [5] [6] [7]. The progress and exploration of its key technologies directly affect the low wind speed. The development of the wind power industry is one of the key development directions of China's renewable energy. 
Wind turbine direct drive permanent magnet generator is one of the development trends of the wind power industry. The permanent magnet generator has high reliability and high efficiency. It can convert wind energy into electric energy effectively in the low wind speed working area, which has great potential for development in wind turbine development.

The composite magnetic circuit permanent magnet wind turbine involved in the project research is main magnetic circuit in the axial direction [2] [8]-[14], The circumferential direction is a secondary magnetic circuit structure similar to the conventional permanent magnet layout, The axial main magnetic circuit and the circumferential cross arrangement make a negative slope linear relationship between the magnetic induction intensity and the air gap, Thereby, the air gap sensitivity of the generator is greatly improved, and the structural design of the permanent magnet generator is more easily realized, the generator cost is greatly reduced, and the engineering practical application is facilitated.

\section{Design of Composite Magnetic Circuit Structure}

Finite element analysis is a very effective tool for finding approximate solutions of complex differential equations.

The structural characteristic of the composite magnetic circuit permanent magnet wind power generator is a rotor structure, and the permanent magnet unit adopts a split structure, a rectangular body magnetic strip and a permanent magnet unit formed by bonding two magnetic poles of $\mathrm{N}$ pole and $\mathrm{S}$ pole, which embedded in the outer rotor structure, this can save permanent magnet materials and reduce production costs.

Through electromagnetic design, the structural parameters of the permanent magnetic wind turbine with composite magnetic circuit structure and the electromagnetic parameters of the no-load characteristic are obtained as shown in Table 1.

The rotor structure model is drawn by the three-dimensional mechanical drawing CAD software Solidworks as shown in Figure 1, which is imported into Maxwell 3D for calculation.

\section{Three-Dimensional Performance Analysis of Composite Magnetic Circuit Permanent Magnet Wind Turbine}

In the static magnetic field, only the permanent magnet is used as the magnetic source, and there is no added excitation in the stator winding. Figure 2 shows the magnetic-density distribution of the curved surface at the center of the air gap. It is very intuitive to see the magnetic-tight distribution on the cylindrical surface. The magnetic density of the magnetic conductive strip is relatively large, and the amplitude is between $0.8 \mathrm{~T}$ and $1.1 \mathrm{~T}$. Magnetic density non-uniformity in the axial direction is exhibited.

There are three operating conditions for permanent magnet wind turbines under transient magnetic fields: no-load operation, load operation and short-circuit faults. 
Table 1. Design specifications and the main structure size.

\begin{tabular}{|c|c|c|}
\hline & Parameters & Value \\
\hline \multirow{5}{*}{ Specifications } & Rated power (W) & 100 \\
\hline & Rated speed (rpm) & 200 \\
\hline & Rated line voltage $(\mathrm{V})$ & 24 \\
\hline & Frequency $(\mathrm{Hz})$ & 50 \\
\hline & Effectiveness & $\geq 75 \%$ \\
\hline \multirow{6}{*}{ Rotor } & Permanent magnet material & $\mathrm{NdFeB}(\mathrm{N} 38 \mathrm{H})$ \\
\hline & Rotor outer diameter (mm) & 164 \\
\hline & Rotor inner diameter $(\mathrm{mm})$ & 135.6 \\
\hline & Rotor length (mm) & 78 \\
\hline & Rotor Yoke length (mm) & 6 \\
\hline & Embedded depth (mm) & 6 \\
\hline \multirow{7}{*}{$\begin{array}{l}\text { Permanent magnet } \\
\text { unit }\end{array}$} & Permanent magnet material & $\mathrm{NdFeB}(\mathrm{N} 38 \mathrm{H})$ \\
\hline & Residual magnetic flux density & 1.28 \\
\hline & Magnetic induction coercivity $(\mathrm{kA} / \mathrm{m})$ & 970 \\
\hline & Permanent magnet pole pair & 30 \\
\hline & Length $\times$ width $\times$ thickness $(\mathrm{mm})$ & $35 \times 7.5 \times 4$ \\
\hline & Magnetic strip material & Silicon steel (DW540) \\
\hline & Magnetic strip size (mm) & $75 \times 7.5 \times 4$ \\
\hline Air gap & Air gap (mm) & 0.8 \\
\hline
\end{tabular}

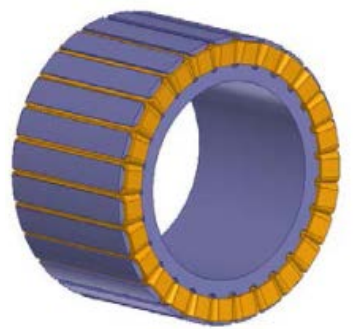

(a)

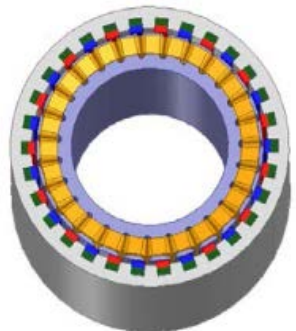

(c)

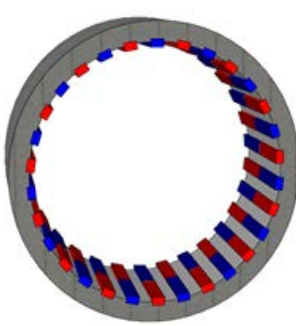

(b)

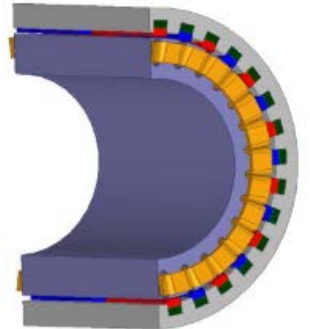

(d)

Figure 1. Rotor structure model. (a) Rotor model; (b) Finite element simulation model; (c) Complete model; (d) Sectional view. 

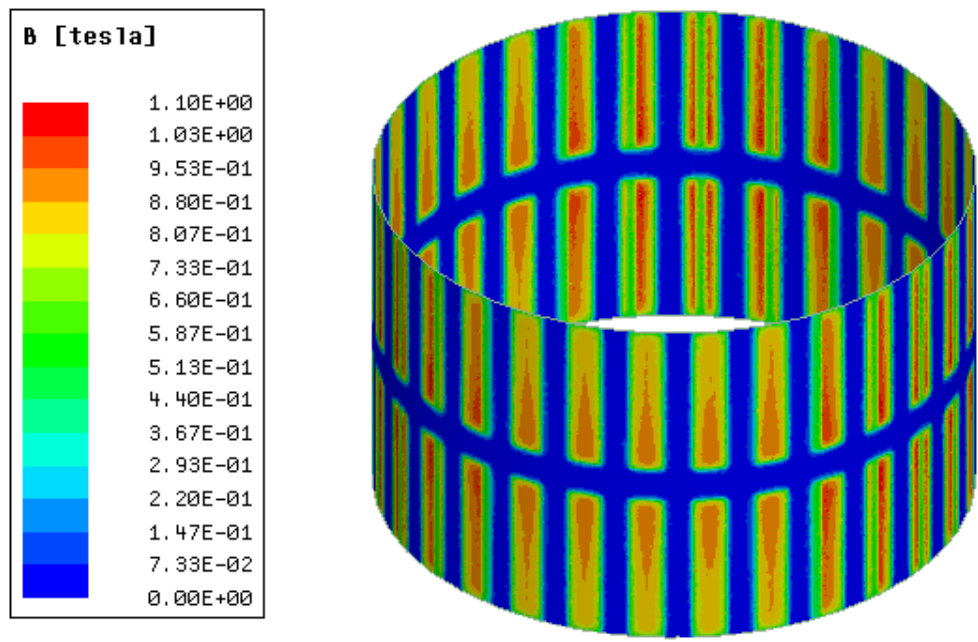

Figure 2. Map of magnetic density distribution.

\subsection{No-Load Operation}

The main magnetic field of the no-load is provided by a permanent magnet, and the magnetic field passes through the air gap and the armature winding. When the rotor rotates, the armature winding cuts the rotating magnetic field line to induce the three-phase AC electromotive force, and the stator winding is called no-load operation when it is open. The no-load characteristic is one of the basic characteristics.

It can be concluded from the Figure 3 that the no-load electromotive force waveform is close to a sine wave with amplitude of $30 \mathrm{~V}$, which satisfies the design requirements; the cogging torque curve is smooth and stable after stabilization as show in Figure 4.

\subsection{Load Operation}

When the permanent magnet generator is under load operation, the armature winding and the external circuit form a closed circuit, and a current will flow, and the armature reaction will in turn affect the distribution and waveform of the air gap magnetic field, thereby affecting the working point of the permanent magnet. The external circuit load during load operation is set to a purely resistive load, and the load resistance value is $5.67 \Omega$ from the rated voltage and power.

Figure 5 shows the three-phase output phase voltage waveform and current waveform with good sinusoidality at rated load. The phase induced electromotive force contains third harmonic. The three-phase winding symmetrical connection cancels the harmonics of multiples of three and three and does not output to the external circuit. Therefore harmonics are greatly suppressed.

\subsection{Short Circuit Faults}

When a three-phase short-circuit fault occurs in the permanent magnet generator, the armature winding current will increase several times instantaneously, the 


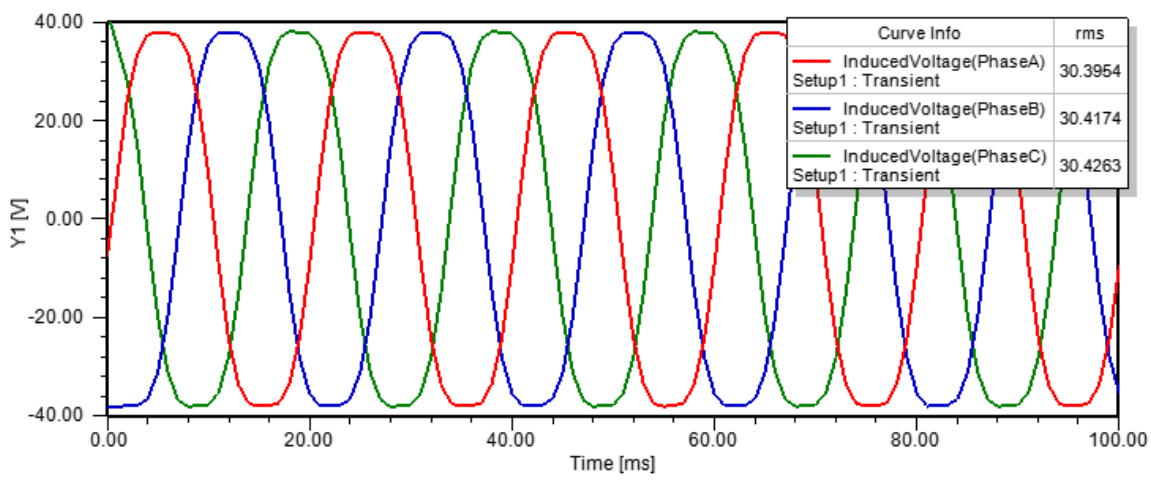

Figure 3. No-load back EMF waveform.

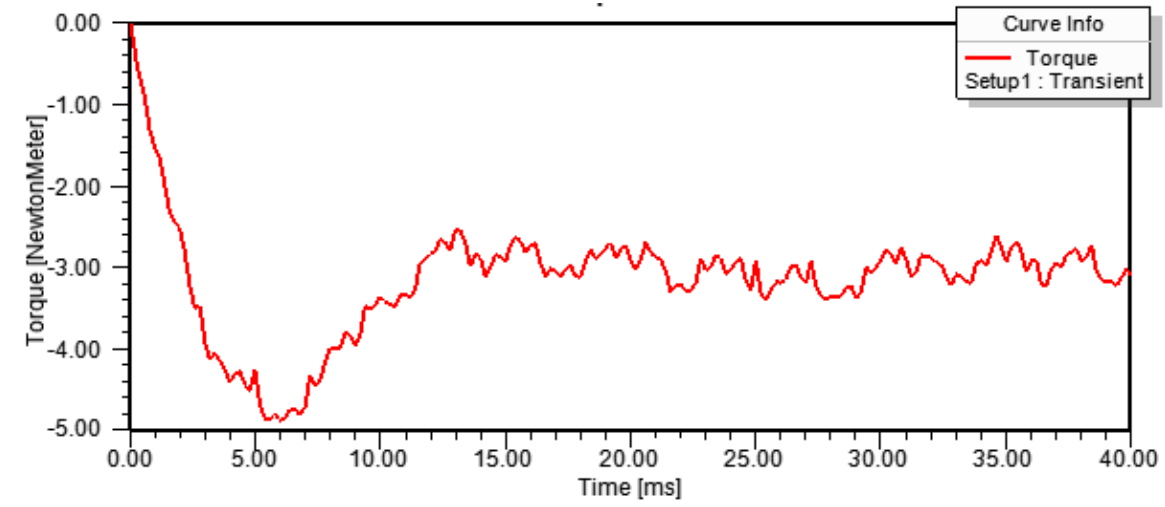

Figure 4. Cogging torque curve.

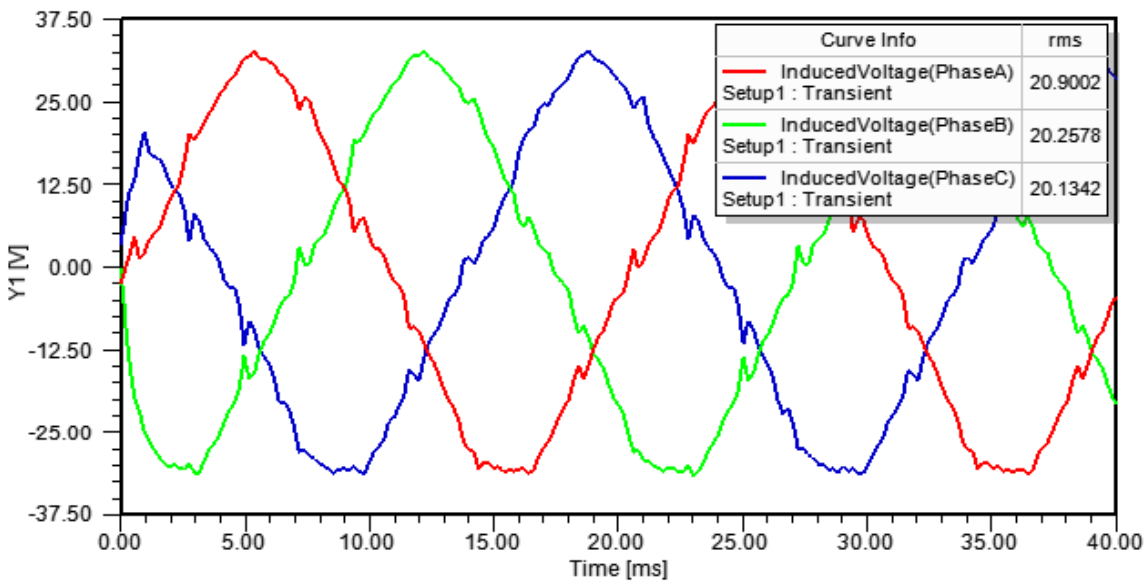

Figure 5. Three phase output voltage under load.

armature reaction will increase, the permanent magnet operating point will drop, whether there will be irreversible demagnetization problems, and the worst three-phase short circuit will be required. The fault is analyzed. In the external circuit, the control of the voltage control switch is controlled, so that the short circuit fault can be simulated at a certain time, the short circuit occurs after the generator runs for one cycle under the rated load, and the short circuit occurs after three cycles to resume normal operation. 


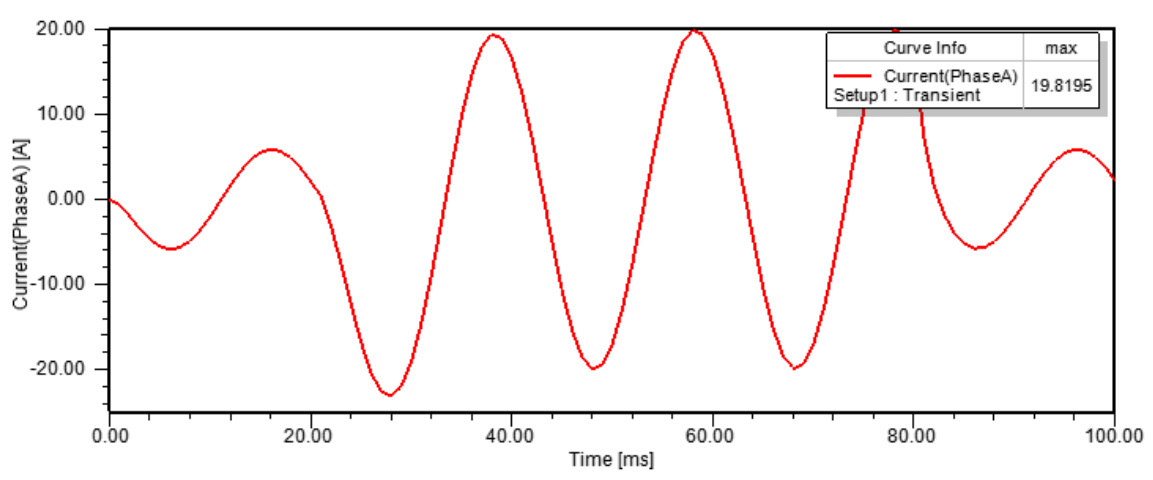

Figure 6. Current curve under short circuit fault.

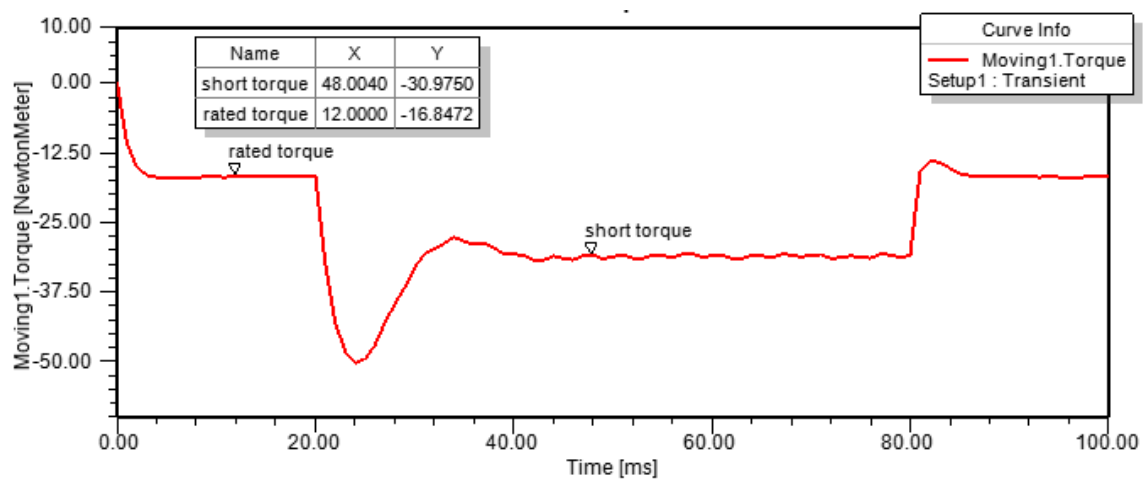

Figure 7. Torque curves under short circuit fault.

Figure 6 shows the short circuit current change waveform. The short-circuit current is six times the load current. The short circuit current increases, causing the motor winding to heat up and the loss is too large. Figure 6 Torque fluctuation curve during short circuit, sudden increase in torque produces vibration and noise, increases mechanical losses, and reduces motor life. From the short circuit of Figure 7, the minimum magnetic density of each permanent magnet is $0.4 \mathrm{~T}$, which is larger than the permanent magnet demagnetization inflection point, so there is no irreversible demagnetization problem.

\section{Conclusion}

The three-dimensional performance analysis results of the new composite magnetic circuit structure permanent magnet wind turbine show the correctness and feasibility of the design method. The structural parameters and the estimated electromagnetic performance of the permanent magnet wind turbine are designed by the field-circuit combination method, which is convenient and quick. Shorten the design cycle and calculate the accuracy to meet the engineering application requirements. At the same time, compared with the traditional radial magnetic circuit structure permanent magnet wind turbine of the same type, the reluctance torque of the permanent magnet wind generator with the new composite magnetic circuit structure is significantly reduced, and its operation is stable and the reliability is high. It is conducive to low wind speed start-up and 
expands the application field of small wind power generation systems. The structure can achieve an efficiency of $80 \%$. It has the characteristics of simple structure, small size and light weight, and is suitable for independent power supply systems.

\section{Acknowledgements}

We most gratefully acknowledge the financial support of the 2017 Henan science and technology plan project No. 172102210246.

\section{Conflicts of Interest}

The authors declare no conflicts of interest regarding the publication of this paper.

\section{References}

[1] Cheng, M. and Zhu, Y. (2014) The State of the Art of Wind Energy Conversion Systems and Technologies: A Review. Energy Conversion and Management, 88, 332-347. https://doi.org/10.1016/j.enconman.2014.08.037

[2] Feng, Y., Lin, H., Ho, S.L., et al. (2015) Overview of Wind Power Generation in China: Status and Development. Renewable and Sustainable Energy Reviews, 50, 847-858. https://doi.org/10.1016/j.rser.2015.05.005

[3] Global Wind Energy Council (2017) http://www.gwec.net/global-figures/graphs/

[4] Zhang, J., Cheng, M. and Chen, Z. (2008) Optimal Design of Stator Interior Permanent Magnet Machine with Minimized Cogging Torque for Wind Power Application. Energy Conversion and Management, 49, 2100-2105. https://doi.org/10.1016/j.enconman.2008.02.017

[5] Eriksson, S. and Bernhoff, H. (2011) Loss Evaluation and Design Optimisation for Direct Driven Permanent Magnet Synchronous Generators for Wind Power. Applied Energy, 88, 265-271. https://doi.org/10.1016/j.apenergy.2010.06.010

[6] Tiegna, H., Amara, Y. and Barakat, G. (2013) Overview of Analytical Models of Permanent Magnet Electrical Machines for Analysis and Design Purposes. Mathematics and Computers in Simulation, 90, 162-177. https://doi.org/10.1016/j.matcom.2012.12.002

[7] Hossain, M.M. and Ali, M.H. (2015) Future Research Directions for the Wind Turbine Generator System. Renewable and Sustainable Energy Reviews, 49, 481-489. https://doi.org/10.1016/j.rser.2015.04.126

[8] Tripathi, S.M., Tiwari, A.N. and Singh, D. (2015) Grid-Integrated Permanent Magnet Synchronous Generator Based Wind Energy Conversion Systems: A Technology Review. Renewable and Sustainable Energy Reviews, 51, 1288-1305. https://doi.org/10.1016/j.rser.2015.06.060

[9] Qin, Z.H. (2014) Electromagnetic Design and Theory Regularity Research of 3 MW Direct-Dirven Permanent Magnet Wind Generator. Harbin University of Science and Technology, Harbin.

[10] Gündoğdu, T. and Kömürgöz, G. (2012) Technological and Economical Analysis of Salient Pole and Permanent Magnet Synchronous Machines Designed for Wind Turbines. Journal of Magnetism and Magnetic Materials, 324, 2679-2686. https://doi.org/10.1016/j.jmmm.2012.03.057 
[11] Fang, H. and Wang, D. (2017) A Novel Design Method of Permanent Magnet Synchronous Generator from Perspective of Permanent Magnet Material Saving. IEEE Transactions on Energy Conversion, 32, 48-54. https://doi.org/10.1109/TEC.2016.2621133

[12] Mizuno, S., Ishikawa, T. and Kurita, N. (2016) Rotor Structure Design of Permanent Magnet Synchronous Generator by Topology Optimization Method Using GA. International Journal of Applied Electromagnetics and Mechanics, 52, 1453-1460. https://doi.org/10.3233/JAE-162128

[13] Kurt, E., Gör, H. and Döner, U. (2016) Electromagnetic Design of a New Axial and Radial Flux Generator with the Rotor Back-Irons. International Journal of Hydrogen Energy, 41, 7019-7026. https://doi.org/10.1016/j.ijhydene.2016.02.034

[14] Gör, H. and Kurt, E. (2016) Preliminary Studies of a New Permanent Magnet Generator (PMG) with the Axial and Radial Flux Morphology. International Journal of Hydrogen Energy, 41, 7005-7018. https://doi.org/10.1016/j.ijhydene.2015.12.195 